\title{
Alarm Clock-Based Reminder for Improving Low Adherence on Option B Plus Antiretroviral Therapy Among HIV Positive Pregnant and Lactating Mothers in Northern Ethiopia
}

This article was published in the following Dove Press journal: HIVIAIDS - Research and Palliative Care

\author{
Gebremedhin Gebreegziabher \\ Gebretsadik (D) ' \\ Hailay Gebretnsae (1D ${ }^{2}$ \\ Mulu Ftwi ${ }^{1}$ \\ Afewerki Tesfahunegn $\left(\mathbb{D}^{3}\right.$ \\ 'Department of Midwifery, College of \\ Health Science, Adigrat University, \\ Adigrat, Tigray, Ethiopia; ${ }^{2}$ Tigray Health \\ Research Institute, Mekelle, Tigray, \\ Ethiopia; ${ }^{3}$ Department of Epidemiology, \\ College of Health Science, Mekelle \\ University, Mekelle, Tigray, Ethiopia
}

Background: Option B plus antiretroviral therapy (ART) is an approach used to eliminate new Human Immune Deficiency Virus (HIV) infections among infants. Considering the high adherence on Option B plus ART in HIV positive mothers is a crucial part in preventing mother-to-child transmission HIV. Therefore, this study was performed to assess the status of adherence and factors related to Option B plus ART.

Methods: A cross-sectional study design was conducted in Eastern zone of Tigrai Region from January to February 2017. Data were collected by using pre-tested structured interviewer-administered questionnaire from 350 participants selected using simple random sampling. Descriptive and binary logistic regression was done during analysis.

Results: The overall good adherence status of Option B plus ART among pregnant and lactating mothers was $67.3 \%$ [62.3-72.3\%]. Attending formal education ( $\mathrm{AOR}=2.78,95 \% \mathrm{CI}$ 1.52-5.07), traveling for $<1$ hour to reach health facility ( $\mathrm{AOR}=2.03,95 \%$ CI $1.19-3.44$ ), (CD4) count $<350$ cells $/ \mathrm{mm} 3$ ( $\mathrm{AOR}=2.3,95 \%$ CI 1.33-3.95), starting their Option B plus during pregnancy $(\mathrm{AOR}=2.08,95 \% \mathrm{CI} 1.08-3.97)$, taking one pill per day $(\mathrm{AOR}=2.12,95 \%$ CI 1.25-3.58), using a clock as a reminder ( $\mathrm{AOR}=2.51,95 \% \mathrm{CI} 1.3-4.86)$, and having good male involvement $(\mathrm{AOR}=2.91,95 \%$ CI 1.64-5.16) were associated with good level of adherence for Option B plus ART treatment.

Conclusion: Our study revealed that the level of good adherence is low compared with the national target. Therefore, addressing the low adherence of Option B plus ART requires a policy response, such as efforts to enhance male partner involvement and better service accessibility in Prevention of Mother-to-Child Transmission (PMTCT) program. Moreover, health care providers and policymakers need to maximaze their efforts on HIV positive pregnant and lactating mothers using a clock as a reminder.

Keywords: adherence, Option B plus ART, Prevention of Mother-to-Child Transmission program; PMTCT, Ethiopia

\section{Introduction}

Option B plus in Prevention of Mother-to-Child Transmission (PMTCT) is a "test and treat" strategy in which triple are started as soon as Human Immune Deficiency Virus (HIV) is detected in a pregnant and lactating woman irrespective of Cluster Differential (CD4) count and the World Health Organization (WHO) stages. ${ }^{1}$ ART is given for life once a day to good drug adherence. Adherence means the client
Correspondence: Gebremedhin Gebreegziabher Gebretsadik

Email gebremedhingebretsad@gmail.com 
accepts, agrees, and correctly follows a prescribed treatment by the health care provider. Option B plus ART is taking prescribed medicines as per the health care provider recommends for both mothers and infant at PMTCT clinic from antenatal diagnosis to the recommended cessation of breastfeeding (18-24 months). ${ }^{1}$

Mainly children are infected by HIV transmitted from women during pregnancy, delivery and the lactating period. Globally, about 3.2 million children under 15 years of age live with HIV, 91\% of these were found in subSaharan Africa. ${ }^{2-5}$

The use of Option B plus ART in women infected with HIV significantly reduces MTCT of HIV. Adherence to ART is an essential and lifelong treatment which needs complete engagement to be effective in viral load suppression, preventing multidrug resistance and reducing the transmission of HIV from mother to child. ${ }^{4,6,7}$

Without receiving any antiretroviral medicines, the rate that HIV positive women can transmit HIV to their children is $30-45 \%$. The goal is to reduce the rate of mother-to -child HIV transmission to less than 5\%.,

Different factors like service delivery of health facilities, referral mechanism, HIV drug resistance with long-term use, acceptability and equity of the service were factors which affected the status of adherence on Option B plus ART., ${ }^{9,10}$ Adherence of Option B plus ART is crucial for pregnant and lactating mothers. But mothers with low adherence of Option B plus ART have increased risk of poor treatment outcome, such as a decrease in viral suppression, an increase in maternal HIV progression, and an increase in the drug-resistance of the virus, which leads to increased risk of mother-to-child transmission. ${ }^{11}$

Ethiopia endorsed the Option B plus PMTCT program which consists of the provision of a single triple-drug ART regimen to HIV positive mothers, with the aim of eliminating MTCT by 2020. ${ }^{12}$ Despite the Ethiopian government implementing different activities to reduce mother-to-child transmission, it did not reach the global plan of a mother-to-child transmission rate of $<5 \%$. The report from the Ministry of Health showed that there is poor adherence to Option B plus ART, and this can have the potential to allow more children to be infected with $\mathrm{HIV}^{13}$

In Tigrai, northern Ethiopia, there is high prevalence of HIV infection in infants (2.1\%). ${ }^{14}$ However, there is limited information on the adherence of Option B plus ART and its related factors. In addition, the adherence of a lactating mother to option B plus ART and related factors is not fully understood. Therefore, this study aimed to provide an insight on the status of adherence to Option B plus ART and related factors in Tigrai, northern Ethiopia.

\section{Methods}

\section{Study Setting and Period}

This study was conducted in the Eastern zone of Tigrai Region, Northern Ethiopia, from January to February 2017. The zone is bounded with Afar in the East, Southeastern Tigrai in the South and Central Tigrai in the West and Eritrea in the North and this zone have seven districts with the capital town of Adigrat. The zone has a population of 850,000 . Of these, 198,900 are women in the reproductive age group. It has two general hospitals, five primary hospitals, 36 health centres, and 116 health posts. Maternal and child health programs, including Option B plus PMTCT program, are given both in hospitals and health centers.

\section{Study Design and Study Populations}

A cross-sectional study design was conducted to assess the adherence level for Option B plus PMTCT program. All HIV positive mothers (both pregnant and lactating) who had follow-up for Option B plus ART in the selected governmental health facilities (health centers and hospitals).

\section{Sample Size Determination}

The sample size was determined by using a single proportion population formula by taking $87 \%$ adherence level for Option B plus, ${ }^{15} 5 \%$ degree of precision and $95 \%$ confidence interval. Finally, after considering 5\% non-response rate and two design effects, the total sample size was 365 .

\section{Sampling Technique and Procedure}

We selected 12 health facilities using a simple random sampling technique from the total of 43 health facilities in Eastern zone of Tigrai, northern Ethiopia. First, we prepared a list of all HIV positive mothers who had enrolled in the PMTCT service in the selected health facilities from the PMTCT registration book, and then the total sample size was allocated proportionally based on the number of mothers at each selected health facility. Finally, we selected 365 mothers by a simple random sampling technique using OPEN EPI software.

\section{Data Collection Tools and Techniques}

A structured questionnaire was adapted from a previous study. ${ }^{16}$ The questionnaire was translated into the local language (Tigrigna) and back to English to keep and see consistency of the original meaning of the questions. The 
data were collected by 12 trained clinical nurse and six BSC nurse supervisors. A pre-test was conducted in $10 \%$ of respondents (36 mothers) in health facilities other than the study sites and some amendments on the questions were undertaken. The collected data were checked by data collectors for completeness and checking for missing data before leaving each study participant. Besides, daily data quality check was done by supervisors and principal investigators.

\section{Measurements of Variables}

Option B plus ART: an approach to all pregnant and lactating HIV positive women who received an Option B plus PMTCT drugs regardless of CD4 count or clinical stages. ${ }^{12}$

Adherence to Option B plus ART: Measurement of good or poor adherence is done by pill count and selfadherence methods. The self-reporting method is more sensitive and acceptable. Thus, the level of adherence was measured by a self-reporting method using four adherence measurement questions adapted from the experience in South Africa, which were designed to measure adherence in resource-constrained setting. ${ }^{16}$ A study participant was considered to have good adherence if she responded "No" to all four of the questions. However, if she responded "Yes" to at least one question, she was considered to have poor adherence.

\section{Male Involvement}

This variable was measured from the total score of 10 questions. Correct answers were given a score of one and incorrect answers were scored zero, and involvement was considered as good for those who scored above the mean and poor for those scored below the mean. ${ }^{15}$

\section{Data Management and Analysis}

Data were entered to Epi-Info version 7 software and then exported to SPSS version 20 for analysis. Data cleaning and editing were carried out before analysis. Frequency distribution and percentages was performed using frequency tables and graphs. Bivariate and multivariable logistic regression analysis was performed to identify the associated factors with adherence of Option B plus ART. All Variables with a p-value $<0.2$ in the bivariate logistic regression analysis were included in to multivariable logistic regression analysis. Finally, variables which had a p-value with $<0.05$ were declared as significantly associated with the adherence of Option B plus ART.

\section{Results}

The Socio-Demographic Characteristics of Study Participants

A total of 350 women participated in the study with a response rate of $96 \%$. The median age of participants was 29 years. Regarding the pregnancy status, 206 (58.8\%) were pregnant and the rest were lactating mothers during the study period. Of the total, $231(66 \%)$ were under 30 years of age and of these, 172 (49.1\%) had good adherence to Option B plus PMTCT treatment (Table 1).

Table I Socio-Demographic Characteristics of Participants in Option B Plus ART Adherence in Eastern Zone of Tigrai, Ethiopia, 2017 ( $N=350)$

\begin{tabular}{|c|c|c|}
\hline \multirow[t]{2}{*}{ Variables } & \multicolumn{2}{|c|}{ Option B Plus Adherence } \\
\hline & Good (\%) & Poor (\%) \\
\hline \multicolumn{3}{|l|}{ Pregnancy status } \\
\hline Pregnant mother & | 44 (4I. I) & $62(17.7)$ \\
\hline Lactating mother & $92(26.3)$ & $52(14.9)$ \\
\hline \multicolumn{3}{|l|}{ Age } \\
\hline$\leq 30$ & $172(49.1)$ & $59(16.9)$ \\
\hline$>30$ & $64(18.3)$ & $55(15.7)$ \\
\hline \multicolumn{3}{|l|}{ Place of residence } \\
\hline Rural & $56(16)$ & $73(20.9)$ \\
\hline Urban & $180(5 \mid .4)$ & $4 I(11.7)$ \\
\hline \multicolumn{3}{|l|}{ Religion } \\
\hline Orthodox & $204(58.3)$ & $90(25.7)$ \\
\hline Muslim & $20(5.7)$ & $4(1.1)$ \\
\hline Protestant\&catholic & $12(3.4)$ & $20(5.7)$ \\
\hline \multicolumn{3}{|l|}{ Marital status } \\
\hline Currently in union & $184(52.6)$ & $75(21.4)$ \\
\hline Currently not in union* & $52(14.9)$ & $39(11.1)$ \\
\hline \multicolumn{3}{|l|}{ Educational status } \\
\hline No formal education & $36(10.3)$ & $48(13.7)$ \\
\hline Formal education & $200(57.1)$ & $66(18.9)$ \\
\hline \multicolumn{3}{|l|}{ Occupational status } \\
\hline Housewife & $140(40)$ & $82(23.4)$ \\
\hline Private employee & $36(10.3)$ & $7(2)$ \\
\hline Merchant & $36(10.3)$ & $3(0.9)$ \\
\hline Government employee & $4(1.1)$ & $3(0.9)$ \\
\hline Student & $16(4.6)$ & II (3.I) \\
\hline Others & $4(1.1)$ & $8(2.3)$ \\
\hline \multicolumn{3}{|c|}{$\begin{array}{l}\text { Time taken to reach a health } \\
\text { facility from home }\end{array}$} \\
\hline$<$ Ihour & $148(42.3)$ & $51(14.6)$ \\
\hline$\geq$ Ihour & $88(25.1)$ & $63(18)$ \\
\hline
\end{tabular}

Note: Currently not in union* (single, widowed, and separated). 


\section{Level of Adherence and Reasons for Poor} Adherence

Overall, 67.3\% (95\% CI 62.3-72.3\%) of respondents had good adherence to Option B plus ART. Of the 115 participants who had poor adherence, the main reasons for not taking Option B plus pills were due to forgetfulness (45\%) and lack of care (15.3\%) (Figure 1).

\section{Behavioral and Clinical Characteristics}

Above half (53.7\%) of mothers who disclose their status to any person had a good level of adherence. Two hundred twelve (60.6\%) mothers who had WHO clinical stage one and two at admission had a good adherence level for Option B plus ART. Regarding the period of Option B plus initiation, twothird (66.3\%), $86(24.6 \%)$, and $32(9.2 \%)$ of mothers had started before the current pregnancy, during pregnancy, and during breast feeding, respectively. Most of the mothers (76.6\%) who had taken ART experienced side effects from the drugs (Table 2).

\section{Factors Related to Level of Adherence on Option B Plus ART}

Thirteen variables (age, place of residence, marital status, educational status, time taken to health facility, disclosure of HIV status, WHO staging, CD4 count at admission, timing of Option B plus starting, number of pills taken per day, experienced side effect, type of reminder to take pills, and male partner involvement) had a p-value $<0.2$ in bivariate analysis and were entered in to the multivariable logistic regression model. Seven of the variables (educational status, time taken to reach a health facility, CD4 count at admission, timing of initiation for Option B plus, numbers of pills taken per day, type of reminder to take pills, and male partner involvement) were independently associated with adherence to Option B plus ART after adjusting for all the other variables (Table 3).

Mothers who attended formal education were 2.78 times more likely to have good adherence to Option B plus ART than those who did not attend formal school. The odds of having good adherence to Option B plus ART among mothers who traveled less than one hour to reach health facility from their home was two times higher than mothers who traveled more than one hour. Mothers whose CD 4 count $<350$ cells $/ \mathrm{mm} 3$ at admission were more likely to have a good adherence level than those who had $\geq 350$ cells $/ \mathrm{mm} 3$ and unmeasured mothers (Table 3).

\section{Discussion}

WHO recommended that, countries should achieve HIV $<50$ new pediatrics per 100,000 live births and a transition rate of either $<5 \%$ in the breast-feeding population or $<2 \%$ in the non- breasting-feeding populations. This is the target for validating elimination of mother-to-child transmission of HIV. ${ }^{17}$ Similarly, the main aim of the government of

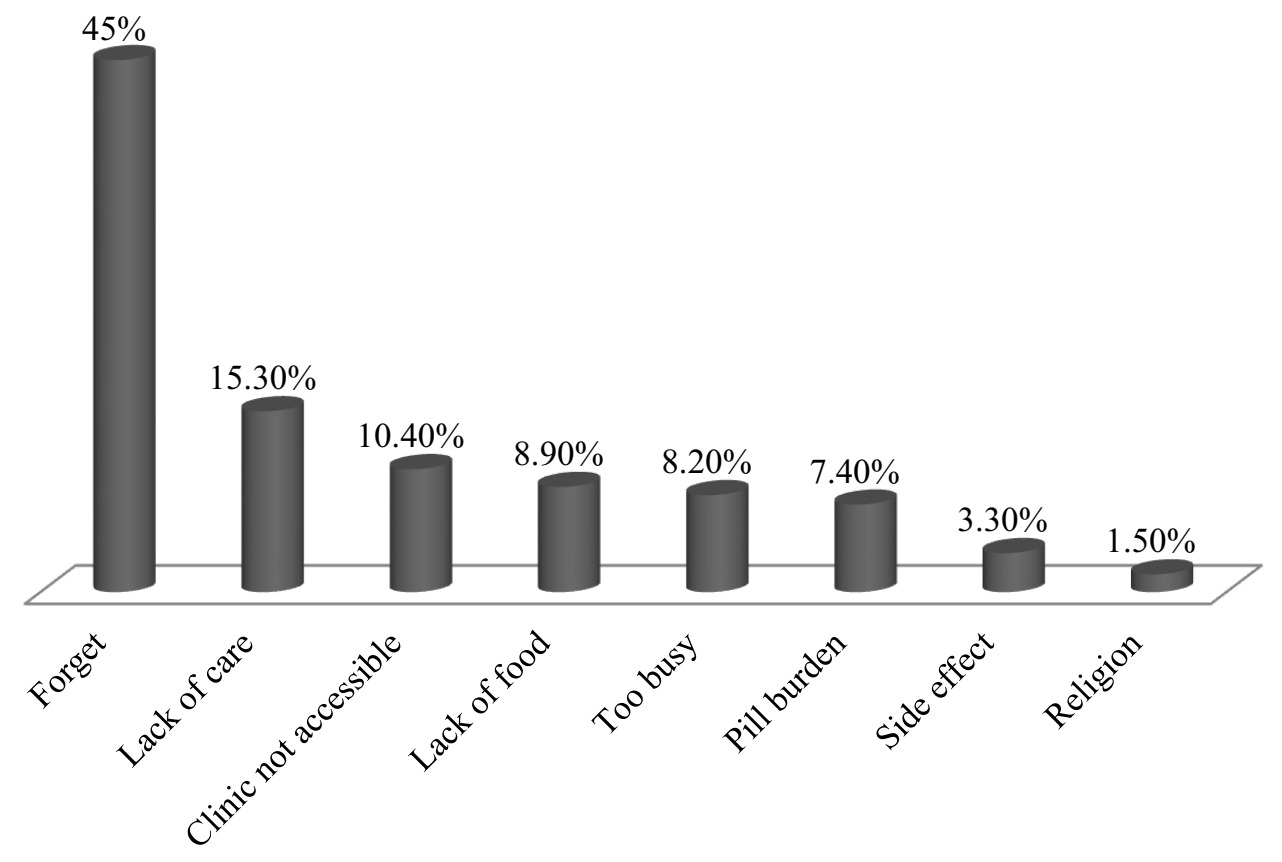

Figure I Reasons for not taking Option B plus ART in eastern zone of Tigrai, Ethiopia, 2017 (N= II5). 
Table 2 Behavioral and Clinical Characteristics of Participants for Option B Plus ART Adherence in Eastern Zone of Tigrai, Ethiopia, $2017(\mathrm{~N}=350)$

\begin{tabular}{|c|c|c|}
\hline \multirow[t]{2}{*}{ Variables } & \multicolumn{2}{|c|}{ Option B Plus Adherence } \\
\hline & Good (\%) & Poor (\%) \\
\hline \multicolumn{3}{|l|}{ HIV status disclosure } \\
\hline Yes & $188(53.7)$ & $78(22.3)$ \\
\hline No & $48(13.7)$ & $36(10.3)$ \\
\hline \multicolumn{3}{|l|}{ Partner HIV positive } \\
\hline Yes & $184(52.6)$ & $67(19.1)$ \\
\hline No & $52(14.9)$ & $47(13.4)$ \\
\hline \multicolumn{3}{|c|}{ WHO clinical stage at admission } \\
\hline Stage I or 2 & $212(60.6)$ & $96(27.4)$ \\
\hline Stage 3 or 4 & $24(6.9)$ & $18(5.1)$ \\
\hline \multicolumn{3}{|c|}{ CD4 count at admission, cells $/ \mathrm{mm}^{3}$} \\
\hline$<350$ & $136(38.9)$ & $44(12.6)$ \\
\hline$\geq 350$ and not measured & $100(28.5)$ & $70(20)$ \\
\hline \multicolumn{3}{|c|}{$\begin{array}{l}\text { Time of initiation of option B plus } \\
\text { treatment }\end{array}$} \\
\hline During this pregnancy & $64(18.3)$ & $22(6.3)$ \\
\hline During breastfeeding & $24(6.9)$ & $8(2.3)$ \\
\hline Previously known & $148(42.3)$ & $84(24)$ \\
\hline \multicolumn{3}{|c|}{$\begin{array}{l}\text { Number of pills taken per day } \\
\text { (including non-ARV) }\end{array}$} \\
\hline I pill & $128(36.6)$ & $44(12.6)$ \\
\hline$\geq 2$ pills & $108(30.9)$ & $70(20)$ \\
\hline \multicolumn{3}{|c|}{ Types of reminder to take medication } \\
\hline Clock & $208(59.4)$ & $85(24.3)$ \\
\hline Others(friends and parents) & $28(8)$ & $29(8.3)$ \\
\hline \multicolumn{3}{|c|}{ Experienced any drugs side effect } \\
\hline Yes & $188(53.7)$ & $80(22.9)$ \\
\hline No & $48(13.7)$ & $34(9.7)$ \\
\hline \multicolumn{3}{|l|}{ Male partner involvement } \\
\hline Poor & $64(18.3)$ & $63(18)$ \\
\hline Good & $172(49.1)$ & $51(14.6)$ \\
\hline
\end{tabular}

Ethiopia to shift Option A to Option B plus was to achieve its ambitious goal of eliminating mother-to-child HIV transmission by 2020. In addition, the Ethiopian government described the level of adherence of Option B plus drug adherence should be equal to or exceed $95 \%$ on the national PMTCT guideline for all prescribed optimized outcomes and minimize the occurrence of viral resistance. ${ }^{12}$ However, in this study only $67.3 \%$ of mothers had good levels of adherence to Option B plus ART. When compared with the aim of the government, this level of adherence to Option B plus was very low. ${ }^{13}$ This is lower when compared with studies reported from sub-Saharan Africa, including Ethiopia and
Nigeria. ${ }^{15,18,20}$ Studies conducted in Ethiopia reported that adherence to Option B plus ART ranged from $81.1 \%$ to $95.1 \%{ }^{15,21-26}$ Moreover, our study is similar to a study conducted in Malawi $(72 \%){ }^{22}$

On the other hand, low adherence was reported among pregnant and lactating women $(52.1 \%)$ and lactating women (44.9 and 51\%) in Uganda. ${ }^{19,20}$ The discrepancy could be due to the differences in the measurement tools of adherence using pill count or self-reporting methods only, or both difference in the adequacy of counseling on adherence to Option B plus ART and educational status among the study participants. Having formal education was found to be a significant predictor of good adherence to Option $\mathrm{B}$ plus ART. The reason might be that having better education allows good access to information and this can help make better informed decision-making. This is supported by a study conducted in Ethiopia, Kenya, Tanzania, and Ghana. ${ }^{15,25,27-29}$

HIV positive women who traveled less than one hour were more likely to have good adherence to Option B plus compared to those who traveled for more than one hour. This is supported by a review study ${ }^{30}$ and a study conducted in Nepal. ${ }^{31}$

Mothers whose CD4 count $<350$ cells/mm3 at admission were more likely to have good adherence level. The possible reason might be that during the immune reconstitute syndrome time, it is plausible that the individual is very conscious and will respect the health providers' help when they feel ill. But if they improve their health status even temporarily, they may be careless and interrupt the use of pills. A study conducted in Nepal showed that there is no a significante relationship between adherence and viral load, ${ }^{32}$ and the reason for this difference could be due to sex and age difference between the studies.

Mothers whose initiation of Option B plus during pregnancy and breastfeeding were good adherence to Option B plus compared with those initiated previously. The reason might be, because of the double burdenin which health care providers emphasize adherence to Option B plus more to pregnant and lactating mothers during counseling. Also, it is well known that mothers fear possible risk to their baby more than for themselves. This is corroborated by the study conducted in Tanzania ${ }^{33}$ which implies that mothers who have initiated ART for PMTCT became less motivated to take the pills right after delivery. A similar study from $\mathrm{Uganda}^{20}$ mentioned that at six months postpartum (51\%) and $12-18$ months (20.5\%) the enrolled mothers were considered to be adherent. The 
Table 3 Factors Associated with Option B Plus ART Adherence in Eastern Zone of Tigrai, Ethiopia, 2017 (N=350)

\begin{tabular}{|c|c|c|c|c|}
\hline \multirow[t]{2}{*}{ Variables } & \multicolumn{2}{|c|}{ Option B Plus Adherence } & \multirow[t]{2}{*}{ COR $(95 \% \mathrm{Cl})$} & \multirow[t]{2}{*}{ AOR (95\% Cl) } \\
\hline & Good (\%) & Poor (\%) & & \\
\hline \multicolumn{5}{|l|}{ Age } \\
\hline$\leq 30$ & $172(49.1)$ & $59(16.9)$ & $2.5 \mathrm{I}(1.57-3.90)$ & $0.8(0.43-1.49)$ \\
\hline$>30$ & $64(18.3)$ & $55(15.7)$ & 1 & \\
\hline \multicolumn{5}{|l|}{ Place of residence } \\
\hline Rural & $56(16)$ & $73(20.9)$ & I & \\
\hline Urban & $180(5 \mid .4)$ & $41(11.7)$ & $5.72(3.52-9.3 I)$ & \\
\hline \multicolumn{5}{|l|}{ Marital status } \\
\hline Currently in union & $184(52.6)$ & $75(21.4)$ & $1.84(1.12-3.02)$ & $0.78(0.35-1.74)$ \\
\hline Currently not in union* & $52(14.9)$ & $39(11.1)$ & I & \\
\hline \multicolumn{5}{|l|}{ Educational status } \\
\hline No formal education & $36(10.3)$ & $48(13.7)$ & I & 1 \\
\hline Formal education & $200(57.1)$ & $66(18.9)$ & $4.04(2.42-6.76)$ & $2.78(1.52-5.07)^{* *}$ \\
\hline \multicolumn{5}{|c|}{ Time taken to reach health facility } \\
\hline$<$ Ihour & $148(42.3)$ & $51(14.6)$ & $2.10(1.32-3.27)$ & $2.03(1.19-3.44)^{*}$ \\
\hline$\geq$ Ihour & $88(25.1)$ & $63(18)$ & 1 & \\
\hline \multicolumn{5}{|l|}{ HIV status disclosure } \\
\hline Yes & $188(53.7)$ & $78(22.3)$ & $1.81(1.10-2.99)$ & $1.21(0.6 \mathrm{I}-2.37)$ \\
\hline No & $48(13.7)$ & $36(10.3)$ & 1 & \\
\hline \multicolumn{5}{|c|}{ WHO clinical stage at admission } \\
\hline Stage 1 or 2 & $212(60.6)$ & $96(27.4)$ & $1.66(0.86-3.20)$ & $0.54(0.26-1.14)$ \\
\hline Stage 3 or 4 & $24(6.9)$ & $18(5.1)$ & I & \\
\hline \multicolumn{5}{|c|}{ CD4 count at admission cells $/ \mathrm{mm}^{3}$} \\
\hline$<350$ & $136(38.9)$ & $44(12.6)$ & $2.16(1.37-3.42)$ & $2.3(1.33-3.95)^{*}$ \\
\hline$\geq 350$ and not measured & $100(28.5)$ & $70(20)$ & I & \\
\hline \multicolumn{5}{|c|}{ Time of initiation of option B plus ART } \\
\hline During this pregnancy & $64(18.3)$ & $22(6.3)$ & $1.65(0.95-2.97)$ & $2.08(1.08-3.97)^{*}$ \\
\hline During breastfeeding & $24(6.9)$ & $8(2.3)$ & $1.70(0.73-3.96)$ & $2.79(1.11-6.98)^{*}$ \\
\hline Previously known & $148(42.3)$ & $84(24)$ & 1 & \\
\hline \multicolumn{5}{|c|}{ Number of pills taken per day (including non-ARV) } \\
\hline I pill & $128(36.6)$ & $44(12.6)$ & $1.89(1.20-2.97)$ & $2.12(1.25-3.58)^{*}$ \\
\hline$\geq 2$ pills & $108(30.9)$ & $70(20)$ & 1 & \\
\hline \multicolumn{5}{|c|}{ Types of reminder to take medication } \\
\hline Clock & $208(59.4)$ & $85(24.3)$ & $2.53(1.42-4.52)$ & $2.51(1.3-4.86)^{*}$ \\
\hline Others (friends and parents) & $28(8)$ & $29(8.3)$ & I & \\
\hline \multicolumn{5}{|c|}{ Experienced any drugs 'side effect } \\
\hline Yes & $188(53.7)$ & $80(22.9)$ & $1.67(0.99-2.78)$ & $0.94(0.43-2.07)$ \\
\hline No & $48(13.7)$ & $34(9.7)$ & I & \\
\hline \multicolumn{5}{|l|}{ Male partner involvement } \\
\hline Poor & $64(18.3)$ & $63(18)$ & I & \\
\hline Good & $172(49.1)$ & $51(14.6)$ & $2.32(1.27-4.23)$ & $2.91(1.64-5.16)^{*}$ \\
\hline
\end{tabular}

Notes: *Statistically significant at $p<0.05 ; * *$ Statistically significant at $p<0.0$. 
reason for decreased levels of adherence could be due to increased use of option B plus drugs.

Mothers who used a clock as a type of reminder were more likely to have a good adherence to Option B plus. The reason could be that due to many social and economic burdens, human can regularly miss a fixed time and friendsor partners do not always live with pregnant and lactating mothers to remind them. On the other hand, a fixed clock is always with the mother and the alarm sounding reminds them to take their pills. Thus, alarm clocks as a reminder - especially in studies in Africa where most participants cited forgetfulness as the main reason for missing doses $27,30,34,35$ - helped to improve adherence.

Mothers who had taken only one pill per day were more likely to have a good adherence to Option B plus as compared with those who had to take two or more pills. The differences observed in our study were consistent with other study. ${ }^{36}$ This might be due to taking a low number of pills, which can decrease the occurrence of side effects and may lead to better adherence.

Male partner support was also found to contribute to improving women's level of adherence on Option B plus ART. This is supported by a study conducted in Tanzania. ${ }^{33}$ The reason might be that male partners can enhance women empowerment that increases the decision to take care of their health.

\section{Limitations}

In this study, the data used to measure the level of adherence were collected using self-reporting from the participants. Though self-reporting is the most commonly used measure of adherence in a resource-limited setting, the result of adherence might still be affected by recall bias.

\section{Conclusions}

In this study, the overall adherence level on the Option B plus was low. This result might be signalizing a regression of the PMTCT program in the Region. Educational status, time taken to reach the health facility, male partner support for PMTCT, CD4 count on admission, timing of initiation for Option B plus, using a clock as a reminder, and the number of pills taken per day were significantly associated with of adherence to Option B plus ART. Addressing the low adherence to the Option B plus program requires a policy response, such as efforts to enhance male involvement in the PMTCT service and to have better service accessibility in PMTCT. Moreover, health care providers and policymakers make more effort to encourage HIV positive pregnant and lactating women to use a clock as a reminder. A longitudinal study that can examine the cause and effect of levels of adherence to the Option B plus PMTCT drug is required.

\section{Abbreviations}

AIDS, Acquired Immune Deficiency Syndrome; ART, Anti Retroviral Therapy; ARV, Anti Retro Virus; CD4, Cluster Differential; HIV, Human Immune deficiency Virus; PMTCT, Prevention Mother-to-Child Transmission; WHO, World Health Organization.

\section{Ethical Approval and Consent of Participants}

The study protocol was reviewed and approved by Adigrat University, College of Medicine and Health Sciences Ethical Review Board (ERC 026/2016). The guideline of our university's of the institutional review board, is in line with the Declaration of Helsinki. Notification expedited approval was obtained after checking by the Health research ethics committee (HRERC) in the guideline that included the Declaration of Helsinki components and principles. In addition, an official letter of cooperation was obtained from Tigrai Regional Health Bureau.Verbal informed consent was obtained from each participant before the interview and the use of verbal consent was approved by the Adigrat University College of Medicine and Health Sciences Ethical Review Board. Confidentiality was assured and participants were informed that they have the right to withdraw from interview at any stage.

\section{Consent for Publication}

Although, the study was received independent individual oral consent and does not report personal data such as individual details, images, or videos, the consent for publication was awarded letter from our institutional review board Health research ethics committee (HRERC).

\section{Acknowledgments}

We acknowledge Adigrat University for financial support during data collection, and for the respondents for their participation in the study.

\section{Author Contributions}

All authors contributed to data analysis, drafting or revising the article, have agreed on the journal to which the article will be 
submitted, gave final approval of the version to be published, and agree to be accountable for all aspects of the work.

\section{Disclosure}

The authors declare that they have no competing interests for this work.

\section{References}

1. World Health Organization. The Strategic Use of Antiretrovirals for Treatment and Prevention of HIV Infection: Report of a WHO Technical Consultation. Geneva: Switzerland; November 14-16, 2011.

2. Joint United Nations Programme on HIV/AIDS (UNAIDS, World Health Organization WHO). AIDS Epidemic Update, 2009. UNAIDS; 2009.

3. Demographic E. Health Survey 2011 Central Statistical Agency Addis Ababa. Maryland, USA: Ethiopia ICF International Calverton; 2012.

4. Besada D, Van Cutsem G, Goemaere E, Ford N, Bygrave H, Lynch S. The case for option B and optional B+: ensuring that South Africa's commitment to eliminating mother-to-child transmission of HIV becomes a reality. South Afr J HIV Med. 2012;13(4):178-181. doi:10.4102/sajhivmed.v13i4.112

5. World Health Organization.Antiretroviral drugs for treating pregnant women and preventing HIV infection in infants: recommendations for a public health approach-2010 version. World Health Organization; 2010.

6. Cooper ER, Charurat M, Mofenson L, et al. Combination antiretroviral strategies for the treatment of pregnant HIV-1-infected women and prevention of perinatal HIV-1 transmission. JAIDSHAGERSTOWN MD. 2002;29(5):484-494.

7. Awittor RJ Adherence to Antiretroviral Therapy (Art) Among Hiv Positive Women at Antiretroviral Centers in Tema [Doctoral dissertation]. University of Ghana;2012.

8. World Health Organization. Global monitoring framework and strategy for the global plan towards the elimination of new HIV infections among children by 2015 and keeping their mothers alive (EMTCT); 2012.

9. Nachega JB, Marconi VC, van Zyl GU, Gardner EM, Preiser W. HIV treatment adherence, drug resistance, virologic failure: evolving concepts. Curr Drug Targets. 2011;11(2):167-174.

10. World Health Organization. Success Factors for Women's and Children's Health: Ethiopia; 2015.

11. Nachega JB, Uthman OA, Anderson J, et al. Adherence to antiretroviral therapy during and after pregnancy in low-, middle and high income countries: a systematic review and meta-analysis. AIDS (London, England). 2012;26(16):2039. doi:10.1097/QAD.0b013e328 $359590 \mathrm{f}$

12. Federal Ministry of Health. The national strategic plan for elimination of mother to child transmission of HIV (e-MTCT of HIV) 2013-2015;2013.

13. Federal H, Prevention Al. Control office, federal ministry of health: single point HIV prevalence estimate; 2007.

14. Desta ML, Saravanan M, Hilekiros H, et al. HIV prevalence and risk factors in infants born to HIV positive mothers, measured by dried blood spot real-time PCR assay in Tigray, Northern Ethiopia. BMC Pediatr. 2019;19(1):257. doi:10.1186/s12887-019-1636-y

15. Ebuy H, Yebyo H, Alemayehu M. Level of adherence and predictors of adherence to the option B+ PMTCT programme in Tigray, northern Ethiopia. Int $J$ Infect Dis. 2015;33:123-129. doi:10.1016/j. ijid.2014.12.026

16. Steel G, Nwokike J, Joshi MP. Development of a multi-method tool to measure ART adherence in resource-constrained settings: the South Africa experience. RPM Plus. 2007;6
17. World Health Organization. Global Guidance on Criteria and Processes for Validation: Elimination of Mother-ToChild Transmission of HIV and Syphilis. 2017.

18. Ekama SO, Herbertson EC, Addeh EJ, et al. Pattern and determinants of antiretroviral drug adherence among Nigerian pregnant women. $\mathrm{J}$ Pregnancy. 2012;23:2012.

19. Noiman A. CHANGES in adherence and program retention and associated factors among hiv-infected women receiving option $b^{+}$ for preventing mother-to-child transmission of hiv in Kampala, Uganda: a mixed methods approach [Doctoral dissertation]. Johns Hopkins University; 2017

20. Decker S, Rempis E, Schnack A, et al. Prevention of mother-to-child transmission of HIV: postpartum adherence to option B+ until 18 months in Western Uganda. PLoS One. 2017;12(6):e0179448. doi:10.1371/journal.pone. 0179448

21. Tsegaye D, Deribe L, Wodajo S. Levels of adherence and factors associated with adherence to option $\mathrm{B}+$ prevention of mother-to-child transmission among pregnant and lactating mothers in selected government health facilities of South Wollo Zone, Amhara Region, northeast Ethiopia, 2016. Epidemiol Health. 2016;38:e2016043. doi:10.4178/epih.e2016043

22. Haas AD, Msukwa MT, Egger M, et al. Adherence to antiretroviral therapy during and after pregnancy: cohort study on women receiving care in malawi's option B+ program. Clin Infect Dis. 2016;63 (9):1227-1235. doi:10.1093/cid/ciw500

23. Shibabaw W, Melkam W, Shiabbaw A. Adherence to anti-retroviral therapy among hiv positive pregnant women in Ayder Refferral Hospital, Northern Ethiopia. J Antivir Antiretrovir. 2018;10 (2):18-22. doi:10.4172/1948-5964.1000175

24. Tadios Y, Davey G. Antiretroviral treatment adherence and its correlates in Addis Ababa, Ethiopia. Ethiop Med J. 2006;44(3):237-244.

25. Lencha MT. Adherence to option B+ and associated factors among pregnant women on pmtct services at public health facilities of East Shawa Zone, Oromia, Ethiopia. J Womens Health Reprod Med. 2018;2(1):2.

26. Belayihun B, Negus R. Antiretroviral treatment adherence rate and associated factors among people living with HIV in Dubti Hospital, Afar Regional State, East Ethiopia. Int Sch Res Notices. 2015;2015.

27. Ayuo P, Musick B, Liu H, et al. Frequency and factors associated with adherence to and completion of combination antiretroviral therapy for prevention of mother to child transmission in western Kenya. J Int AIDS Soc. 2013;16(1):17994. doi:10.7448/IAS.16.1.17994

28. Kirsten I, Sewangi J, Kunz A, et al. Adherence to combination prophylaxis for prevention of mother-to-child-transmission of HIV in Tanzania. PLoS One. 2011;6(6):e21020. doi:10.1371/journal.pone.0021020

29. Boateng D, Kwapong GD, Agyei-Baffour P. Knowledge, perception about antiretroviral therapy (ART) and prevention of mother-to-childtransmission (PMTCT) and adherence to ART among HIV positive women in the Ashanti Region, Ghana: a cross-sectional study. BMC Womens Health. 2013;13(1):2. doi:10.1186/1472-6874-13-2

30. Shubber Z, Mills EJ, Nachega JB, et al. Patient-reported barriers to adherence to antiretroviral therapy: a systematic review and meta-analysis. PLoS Med. 2016;13(11):e1002183. doi:10.1371/journal.pmed. 1002183

31. Wasti SP, Simkhada P, Randall J, Freeman JV, Van Teijlingen E. Factors influencing adherence to antiretroviral treatment in Nepal: a mixed-methods study. PLoS One. 2012;7(5):e35547. doi:10.1371/ journal.pone.0035547

32. Pramila K, Gharti KP, Sharma S. Effect of adherence to anti-retroviral therapy on cd4 t cells and hiv viral load in Nepalese Tertiary Care Hospital; 2017.

33. Kapesa A, Magesa D, William A, Kaswija J, Seni J, Makwaya C. Determinants of immunological failure among clients on the first line treatment with highly active antiretroviral drugs in Dar es Salaam, Tanzania. Asian Pac J Trop Biomed. 2014;4:S620-4. doi:10.12980/APJTB.4.2014APJTB-2013-0035 
34. Kim MH, Zhou A, Mazenga A, et al. Why did I stop? Barriers and facilitators to uptake and adherence to ART in Option B+ HIV care in Lilongwe, Malawi. PLoS One. 2016;11(2):e0149527. doi:10.1371/journal.pone.0149527

35. Atanga PN, Ndetan HT, Fon PN, et al. Using a composite adherence tool to assess ART response and risk factors of poor adherence in pregnant and breastfeeding HIV-positive cameroonian women at 6 and 12 months after initiating option $\mathrm{B}+$. BMC Pregnancy Childbirth. 2018;18(1):418. doi:10.1186/s12884-018-2058-9
36. Cohen CJ, Meyers JL, Davis KL. Association between daily antiretroviral pill burden and treatment adherence, hospitalisation risk, and other healthcare utilisation and costs in a US medicaid population with HIV. BMJ Open. 2013;3(8). doi:10.1136/bmjopen-2013003028

HIV/AIDS - Research and Palliative Care

\section{Publish your work in this journal}

HIV/AIDS - Research and Palliative Care is an international, peerreviewed open-access journal focusing on advances in research in HIV, its clinical progression and management options including antiviral treatment, palliative care and public healthcare policies to control viral spread. The manuscript management system is completely online and includes a very quick and fair peer-review system, which is all easy to use. Visit http://www.dovepress.com/testimonials.php to read real quotes from published authors. 